\title{
Laboratory Cultivation of Some Human Parasitic Amoebae
}

\author{
By G. L. ROBINSON \\ Seamen's Hospital, Greenwich, London, S.E. Io \\ (Accepted for publication I3 March 1968)
}

SUMMAR Y

Cultural conditions and supplementary substances necessary for the laboratory cultivation of some human parasitic amoebae were investigated by using a basal solution containing inorganic salts, citrate and lactate. Three supplementary components were found necessary: starch grains, animal protein (soluble or insoluble) and living bacteria. Restraint of bacterial growth by antibiotics, and of the development of an alkaline reaction (due to pellicleforming aerobes) by carbon dioxide, improved the amoebic growth. Under these conditions, all the common parasitic amoebae examined, except Iodamoeba butschlii, were grown and maintained for long periods in laboratory culture.

\section{INTRODUCTION}

This work began with the observation of Entamoeba histolytica trophozoites in a culture after incubation for $24 \mathrm{hr}$ at $37^{\circ}$ of cyst-containing faeces suspended in a simple defined medium suitable for growing Escherichia coli (Robinson, 195I). A method for cultivating the parasitic amoebae was then developed in which a liquid culture of $E$. coli in this defined medium + starch + erythromycin was overlaid on a slope of saline agar in a quarter-ounce screw-capped bottle (gas-phase air) and inoculated with cyst-containing faeces (of normal bacterial content). By this process $E$. histolytica was grown in primary culture and in the first subculture, while other amoebic species occasionally appeared in recognizable numbers. But even when normal (i.e. amoebafree) faeces was added, further amoebic subcultures did not grow. It was decided to examine the nature of the supplements which were needed to obtain continuous subculture of amoebae in $E$. coli cultures in the defined medium +starch + erythromycin overlaid on saline agar.

\section{METHODS}

Saline agar slopes. Agar $\mathrm{I} \cdot 5 \%(\mathrm{w} / \mathrm{v})+\mathrm{NaCl} 0.7 \%(\mathrm{w} / \mathrm{v})$ in water was distributed in $2.5 \mathrm{ml}$. volumes in quarter-ounce screw-capped glass bottles and sloped after autoclaving.

Antibiotics. Solutions of erythromycin, ristocetin and streptomycin $(0.5 \%, \mathrm{w} / \mathrm{v})$, chloramphenical $(0 \cdot 2 \%, \mathrm{w} / \mathrm{v})$ and polymyxin (5000 units $/ \mathrm{ml}$.) were used.

Rice starch. Rice powder (British Drug Houses Ltd.) after drying was dry-sterilized in partly filled quarter-ounce bottles with caps screwed tight.

Phthalate $(0.05 \mathrm{M})$ diluent. Potassium hydrogen phthalate $10.02 \mathrm{~g}$. and sodium hydroxide $2 \mathrm{~g}$. were dissolved in $\mathrm{I} 1$. water, adjusted to $\mathrm{pH} 6.5$ and the solution autoclaved.

Defined medium $R$ for growing Escherichia coli. Concentrated stock solution consisted of I25 g. sodium chloride, $50 \mathrm{~g}$. citric acid monohydrate, $12.5 \mathrm{~g}$. potassium 
dihydrogen phosphate, $25 \mathrm{~g}$. ammonium sulphate, $\mathrm{I} \cdot 25 \mathrm{~g}$. magnesium sulphate heptahydrate and $100 \mathrm{ml}$. lactic acid (British Drug Houses Ltd., 90.08\%) in 2.51. water. For $\mathrm{R}$ medium, one volume of concentrated stock solution was diluted with nine volumes of $0.33 \%(\mathrm{w} / \mathrm{v})$ sodium hydroxide, adjusted to $\mathrm{pH} 7$ and autoclaved. Stock more than 4 weeks old was used to avoid $\mathrm{pH}$ change on autoclaving.

Basal amoebic medium BR. Escherichia coli strain B was incubated for $48 \mathrm{hr}$ at $37^{\circ}$ in shallow layers of medium $R$ in sealed flat bottles; this living culture was the basal medium BR.

Supplemented media for amoebic growth. The general method of preparing supplemented media was to boil a proposed supplement in medium $\mathrm{R}$, filter through Whatman no. I paper, autoclave the filtrate at $\mathrm{pH} 7$, inoculate with Escherichia coli $\mathrm{B}$, incubate at $37^{\circ}$ in shallow layers for $48 \mathrm{hr}$ and store the living culture at room temperature until required. Media with 70 different complex supplements were thus prepared; the main supplements used are indicated in Table I; the preparation of four are described below:

Medium BRS (serum added). Equal volumes of medium BR and Seitz-filtered heated $\left(56^{\circ}\right)$ serum (sheep) were mixed and incubated for $48 \mathrm{hr}$ at $37^{\circ}$. Sheep serum was better than any other.

Medium BRMt (serum metaprotein added). Metaprotein (Cole, 1919) was prepared to exclude soluble (at $\mathrm{pH}$ 7) material, by sulphosalicylic acid precipitation of human serum. The precipitate was washed with water, the suspension boiled, dissolved in $\mathrm{NaOH}$, filtered, re-precipitated by acetic acid and the precipitate washed for 4 days, and autoclaved as an aqueous cream. For use, $5 \mathrm{ml}$. was added to $100 \mathrm{ml}$. medium R, (adjusted to $\mathrm{pH} 7$ ) steamed, inoculated with Escherichia coli $\mathrm{B}$ and incubated.

Medium BRT (tripe extract added). Tripe (500 g.) was sliced into I cm. cubes, boiled with $\mathrm{I}$ l. medium $\mathrm{R}$ for $4 \mathrm{hr}$ on 3 successive days, filtered through lint, the extract autoclaved, inoculated with Escherichia coli B and incubated.

Medium BRG (gastric mucin added). Gastric mucin (Armour) was triturated in medium $\mathrm{R}$ to give $\mathrm{I}$ or $2 \%(\mathrm{w} / \mathrm{v})$, autoclaved, inoculated with Escherichia coli $\mathbf{B}$ and incubated.

The inocula of amoebae used and the maintenance of the amoebic cultures. Except for two strains of Entamoeba histolytica, all the amoebae used were derived from the faeces of patients and were subcultured two or three times weekly in phthalate dilutions ( $1 / 2$ to $1 / 10$ ) of medium BRS and medium BRT, containing antibiotic (usually erythromycin) and starch, as a liquid overlay on the saline agar slopes. Bactopeptone was of ten added to about $0.2 \%$. All cultures were cleared of Blastocystis and in later work Pseudomonas aeruginosa.

Method for removal of Blastocystis. Culture sediment (0.4 $\mathrm{ml}$.) was allowed to settle for $2 \mathrm{~min}$. in $4 \mathrm{ml}$. of $0 \cdot \mathrm{I} \mathrm{N}-\mathrm{HCl}$, the fluid removed and the remaining settled fragments taken up in a few ml. of liquid overlay from the culture to be inoculated (Smedley, 1956).

Methods for antagonizing bacteria in amoebic cultures. These methods were required for two purposes: $(a)$ the elimination of bacterial species, $(b)$ the slowing of multiplication of a mixed flora on which the present medium is based. The interactions of the bacterial species in these amoebic cultures were too complex for their control to be anything but empirical; no transfer of trophozoites (as opposed to cysts) was possible in the absence of living bacteria in the inoculum (apart from the presence of Escherichia coli in the culture medium). For purpose (a) four or five successive amoebic sub- 
cultures were made in medium diluted to the maximum degree (by medium $\mathbf{R}$ or phthalate solution) which permitted the amoebae to grow at all, and containing the appropriate antibiotic. For total elimination of bacteria a prolonged series of tests on successive amoebic subcultures was needed to be sure that an apparently eliminated bacterial species had not become latent. For purpose $(b)$ continuous dosage with antibiotic (usually erythromycin I0-200 $\mu \mathrm{g}$. $/ \mathrm{ml}$.) was added to the medium. When bacterial aerobes increased, to the detriment of amoebic growth (see later), a stream of carbon dioxide was used to displace most of the air above the culture for a few seconds before screwing up the cap of a bottle (this process was also used with polymyxin for elimina-

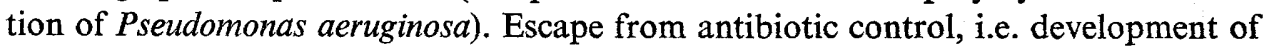
resistance in the bacterial flora of amoebic cultures, was the commonest cause of the dying out of amoebae kept for long periods as stock strains. This occurred more commonly when chloramphenical or penicillin was used than with erythromycin. It was corrected by dispersion of whole sediment from an amoebic culture in saline medium containing several antibiotics in high dosage. After settling for $30 \mathrm{~min}$. the saline solution was replaced by amoebic culture medium + starch, the whole process (growth + treatment) being done, as often as necessary, in $9 \mathrm{ml}$. volume in a screwcapped one-ounce bottle without a saline agar slope.

Testing for amoebae in supplemented media. The various supplemented media (after Escherichia coli B had been grown in them) were diluted $\mathrm{I} / 2$ to $\mathrm{I} / \mathrm{IO}$, usually with phthalate diluent, occasionally with medium $\mathrm{R}$ or medium $\mathrm{BR},+$ starch + antibiotic solution, and overlaid on saline agar slopes at the time of inoculation with amoebae. Sediment from the first bottle was then transferred, after $I-4$ days at $37^{\circ}$, to a second similar bottle, and so on, until a sufficient number of subcultures showed that the amoebae grew continuously in the given medium. Microscopic examination of wet preparations in iodine solution was the means of assessment; this gave information about the state of the starch, the bacteria, the degree of protein coagulation and the carbohydrate metabolism (colour in iodine) of the trophozoites, as well as their number, size and disposition (clumped or diffuse). Generally, number and size of trophozoites, indicating satisfactory growth, ran parallel (in small as well as large species) to iodine-staining of the cytoplasm, which itself constituted a criterion of good growth. From this information, variations and replications were made as the amoebic subculture series proceeded, to prolong it as far as possible.

\section{CONCLUSIONS}

Growth maxima from the main groups of supplemented media are shown in Table $\mathrm{I}$. Because different strains of the same amoebic species did not always give the same results on the same medium it was concluded that the effect of the supplement on the amoebic growth was because of the accompanying bacteria. This was supported by the observed lag in amoebic growth on first transferring a species from one supplemented medium to another, which suggested that adaptation of the bacterial flora was involved. It also accorded with the fact that continual adjustment of concentration and type of antibiotic was one of the principal means by which prolonged growth of the protozoal series was obtained with the less easily grown amoebic species and less effective ented supplemmedia. Another means of affecting the bacterial flora, and so prolonging a series of amoebic subcultures, was by addition of some of the substances (particularly 
Bacto-peptone and Lab-Lemco) shown at the end of Table $I$ as incapable of supporting amoebic growth by themselves alone.

For Entamoeba coli, Entamoeba hartmanni and Endolimax nana, a single strongly growing strain of each was selected for the experiments. For Dientamoeba fragilis, two strains were used which, though mainly similar in behaviour on the various supplements, were different on medium BRG ('Newman' died after 53; 'Raja' after I 7 subcultures) and with a mucoid material prepared from human colon (Newman 2, Raja 2I subcultures). For Entamoeba histolytica, 8 strains were used and discrepancies

Table I. Maximum numbers of positive serial subcultures obtained with different species of human parasitic amoebae with various supplements

Figures with + indicate that amoebae were still growing when discarded; figures without + indicate that amoebae died at this stage.

Protozoa

Source Media and supplements, etc.

Serum

BRS; basal medium + serum (see

Methods)

BRMt; basal medium + metaprotein

(see Methods)

Extract of heat-coagulated human serum

Same, Seitz-filtered

Inspissated serum slope + phthalate extract overlay after BR

Seromucoid (Winzler et al. 1948)

Colon Human colonic mucoid purified (Hawk, 1923)

Tendon Ox tendo-mucoid (Hawk, 1923)

Stomach BRT (see Methods)

Tripe mucoid (Hawk, I923)

BRG (see Methods)

Muscle

Extract of horse muscle

$\mathrm{NaOH}$ extract of ox heart, pptd. by

$\mathrm{HCl}$, washed, used solid

Filtrate from previous

Liver

Extract of human liver

Fish

Extract of tinned salmon

Extract of fresh plaice

Hen eggs Extract of hard-boiled eggs

Gelatin

Steamed at $2 \%(w / v)$ in $R$

As previous, but incubated with

Proteus mirabilis (instead of Escherichia coli)

Yeastrel, Marmite, Lab-Lemco, Bacto-peptone, Proteose peptone, Bacto-casitone, Bacto-casamino-acids, asparagine, glucosamine, cholesterol, fish solubles, distiller's solubles, vegetable mucoid from Plantago coronopus, faeces and controls of BR without supplement.

\begin{tabular}{|c|c|c|c|c|}
\hline 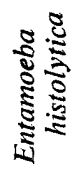 & $\begin{array}{l}-\pi \\
8 \\
\dot{8}\end{array}$ & 志 & 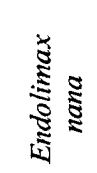 & 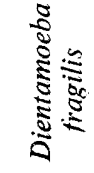 \\
\hline $100+$ & $100+$ & $100+$ & $100+$ & $100+$ \\
\hline $57+$ & $40+$ & $20+$ & $63+$ & $11+$ \\
\hline $30+$ & $14+$ & 16 & $14+$ & $14+$ \\
\hline $\begin{array}{l}15+ \\
18+\end{array}$ & $\begin{array}{c}3 \\
20+\end{array}$ & $\stackrel{13}{8+}$ & $\stackrel{2}{28}+$ & $\begin{array}{l}0 \\
8+\end{array}$ \\
\hline $16+$ & $9+$ & $16+$ & $8+$ & 2 \\
\hline $12+$ & 27 & 8 & 2 & $2 \mathrm{I}$ \\
\hline $10+$ & $5+$ & 2 & 5 & 0 \\
\hline $\begin{array}{l}64+ \\
13+\end{array}$ & $\begin{array}{c}78+ \\
4\end{array}$ & $\begin{array}{l}16+ \\
16\end{array}$ & $\begin{array}{r}112+ \\
22+\end{array}$ & $\begin{array}{l}63+ \\
10\end{array}$ \\
\hline $50+$ & 49 & 40 & 41 & 53 \\
\hline $22+$ & 2 & 0 & 0 & 2 \\
\hline $15+$ & I & $22+$ & 4 & 13 \\
\hline 2 & 0 & I & I & I \\
\hline 14 & I & 2 & 2 & 4 \\
\hline $25+$ & 2 & 0 & 5 & 8 \\
\hline IO & I & 0 & 0 & 0 \\
\hline $16+$ & $12+$ & $12+$ & 4 & $17+$ \\
\hline 3 & 3 & 2 & 2 & 2 \\
\hline 5 & 11 & 3 & 2 & I \\
\hline$<3$ & $<3$ & $<3$ & $<3$ & $<3$ \\
\hline
\end{tabular}


occurred from the maxima recorded in Table $\mathrm{I}$ : one died after 8 subcultures on inspissated serum, two after 3 with fibrinogen extract, one after 4 with horse-meat extract and two after 3 with plaice extract. Differences observed between species (e.g. E. hartmanni required more concentrated supplement and more varied antibiotic control of bacteria, than $E$. histolytica) were like those found between more and less fastidious strains of one amoebic species. This suggested that the nutritional requirements of the various parasitic amoebae differed in degree but not in kind. If it be assumed that the maximum amoebic survival (owing to traces of growth factor in the inoculum and in some of the cultures themselves) is three subcultures, then the results of Table $I$ indicate that many bacterial nutrients (final group in Table I) were incapable of supporting amoebic growth, but that protein supplements were able to do so. When protein was completely removed from any of the supplements amoebic growth did not occur. For example, fibrinogen was removed from solution as coagulum on autoclaving; the resulting clear solution did not support amoebic growth. But a cloudy suspension of fibrinogen, prepared by repeated heating, trituration and lint filtration, gave the amoebic growth maxima shown in Table I. The clearest extracts shown in Table I were those from human liver, plaice and horse meat, which give poor amoebic growth maxima. The point was confirmed by showing that the removal of 'cloud' by the Seitz filter removed also the property of supporting amoebic growth, e.g. from medium BRG in Table I, except in the case of seromucoid, which (unlike the tissue mucoids) passed the Seitz filter and was not coagulated by heat.

Table 2. Insufficiency of either phosphotungstic precipitate ( $X: I \mathrm{ml}$.) or filtrate ( $Y: 1 \mathrm{ml}$.) of deproteinized mucoid-containing serum filtrate to support two successive cultures (a) and (b) of Entamoeba histolytica and Entamoeba coli, unless reinforced by extract ( $Z: I \mathrm{ml}$.) of heat-coagulated whole serum in $R$ medium.

\begin{tabular}{|c|c|c|c|c|c|c|c|}
\hline \multirow{3}{*}{ Bottle } & \multirow{3}{*}{\multicolumn{3}{|c|}{$\begin{array}{c}\text { Composition of } 3 \mathrm{ml} \text {. } \\
\text { overlay, with starch } \\
\text { grains +erythromycin } \\
20 \mu \mathrm{g} . / \mathrm{ml} \text {. on saline } \\
\text { agar slope }\end{array}$}} & \multicolumn{4}{|c|}{ Trophozoites/ml. after 3 days incubation } \\
\hline & & & & \multicolumn{2}{|c|}{ Entamoeba histolytica } & \multicolumn{2}{|c|}{ Entamoeba coli } \\
\hline & & & & (a) & (b) & (a) & (b) \\
\hline I & $\mathrm{X}$ & BR & $\mathbf{R}$ & 10,000 & 0 & 0 & o \\
\hline 2 & $\mathbf{Y}$ & BR & $\mathrm{R}$ & 0 & 0 & 0 & 0 \\
\hline 3 & $\mathrm{X}$ & Y & $\mathbf{R}$ & 3,000 & 0 & 1,000 & 0 \\
\hline 4 & $x$ & BR & Z & 50,000 & 26,000 & 35,000 & 31,000 \\
\hline 5 & $\mathbf{Y}$ & BR & Z & 75,000 & 16,000 & 30,000 & 13,000 \\
\hline
\end{tabular}

An experiment with one strain of Entamoeba histolytica and one of Entamoeba coli showed that the efficiency of serum as growth factor was not simply due to its seromucoid content: when deproteinized serum filtrate containing seromucoid was separated by phosphotungstic acid into mucoid-containing precipitate incorporated in medium BR at about $0.1 \%(\mathrm{w} / \mathrm{v})$, as in serum, and into mucoid-free filtrate similarly incorporated (after dialysis) in medium BR, both supplements needed addition of cloudy filtrate of heat-coagulated whole serum boiled in medium $\mathrm{R}$ to restore amoebic growth in subculture (Table 2).

The suitability of mucoid supplement as amoebic growth supplement led to a test of 
gastric mucin (Armour and Co.), with which (alone of the manufactured products tested) long runs of subcultures sometimes resulted. Continuously viable cultures of Entamoeba histolytica with centrifuged $0.05 \%(\mathrm{w} / \mathrm{v})$ commercial gastric mucin in saline were reported by Dolkart \& Halpern (1958) who stated that their results were improved by adding small amounts of egg medium.

Once the need for protein for amoebic growth became clear, the question was: were proteolytic bacteria necessary to split it? Accordingly, the bacteria accompanying some of the Entamoeba histolytica strains were examined after the amoebae had grown. Anaerobic plates showed predominance of Escherichia coli but aerobically heavy growths of Aerobacter, Achromobacter, Proteus and Pseudomonas species occurred; Streptococcus faecalis was always present and Clostridium species absent. After elimination of the proteolytic Proteus, Pseudomonas and Bacillus species by the technique given above, serial amoebic subcultures were made on medium BRMt with parallel inoculations into nutrient gelatin at each transfer. Of 36 such cultures, most showed gelatin liquefaction after 3 days and all but two after 14 days. The organism responsible was found to be a proteolytic variety of $S$. faecalis which was impossible to eliminate; although it could be decreased apparently to zero for a time, it always reappeared in the cultures. Two Entamoeba histolytica strains were isolated monoxenically from faecal cysts by the method of Singh, Das \& Saxena (1963) by using $24 \mathrm{hr}$ instead of the recommended $48 \mathrm{hr}$ in dilute $\mathrm{HCl}$ suspension and inoculation into overlays of BRS and BRT media with starch and erythromycin (10 $\mu \mathrm{g} . / \mathrm{ml}$ ). Blastocystis (one strain) grew but was removed by sedimentation in $\mathrm{HCl}$ solution (above). Both these strains were successfully transferred to medium BRMt and gave runs of more than 8 serial subcultures, tested by parallel inoculations of aerobic and anaerobic plates at $37^{\circ}$ and $25^{\circ}$, as well as by inoculation on nutrient gelatin. The plates showed Escherichia coli $\mathbf{B}$ to be the only organism accompanying the amoebae; 30 gelatin controls did not liquefy in 14 days.

The finding that proteolytic bacteria were not essential for Entamoeba histolytica and, by inference, for the other strains used, supported the idea that no liquid amoebic growth factor was liberated by bacteria from protein. Attempts to grow amoebae by the diffusion of growth factor through agar layers or viscose sacs always failed.

At this point the microscopical appearance of the cultures became relevant, for it had been noticed that the growth of all amoebic species tended to be in foci, the individuals being clustered upon bacterial colonies. Plate I, fig. I, 2 give a crosssection of the trophozoites in such clusters. Over I00 Endolimax nana individuals were calculated to be present in the bunch shown in Pl. I, fig. 2. The failure to find a soluble metabolite suggested that the trophozoites might be ingesting protein fragments directly, hence they appeared to be clumped on the bacterial colonies, but were really on the protein beneath. Microscopic study of the sediments from BRMt cultures left no doubt that this was not so: the trophozoites could be seen in contact with bacterial networks which had often formed around protein fragments; but to these fragments themselves no trophozoites were ever seen to be attached. Plate I, fig 3 shows such an arrangement in the case of Entamoeba coli. Because the outline of the protein fragment was sacrificed in focusing the amoebae, a diagram of the positions in the microphotograph is given beside it. The conclusion of this part of the work was therefore that 'amoebic growth factor' was ingested by trophozoites in the form of protein-nourished bacterial bodies. 


\section{The gas phase in amoebic cultures}

Experiment $I$. For growth of my amoebae in the manner described above, it was not necessary to tighten the cap of the bottle; but growth did not occur in a shallow layer of supplemented BR medium + starch + antibiotic in an open container without a saline agar slope. This observation was investigated by serial subcultures of Entamoeba histolytica under varied physical conditions in $0.8 \mathrm{ml}$. volumes of medium BRS and medium BRG in $70 \times \mathrm{II} \mathrm{mm}$. tubes in a moist incubator. Figure I gives as a diagram the conditions and amoebic counts (at peak) with medium BRG. The results showed that continuous serial subcultures were possible under these conditions: $(a)$ with $1.5 \mathrm{ml}$. saline agar slope; $(b)$ with slope replaced by a glass rod of equal volume; $(c)$ with bung in tube, but not under conditions $(d)$ with open tube in standard bacteriological anaerobic jar (pure hydrogen); $(e)$ with open tube in air. When the height of the liquid

(a)

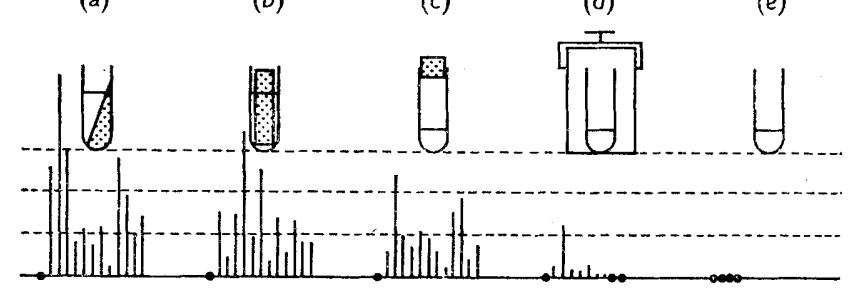

Fig. I. Growth of Entamoeba histolytica under five physical conditions in $70 \times \mathrm{II} \mathrm{mm}$. tubes, containing starch and $0.8 \mathrm{ml}$. volumes of medium BRG diluted $\mathrm{I} / 5$ in R with erythromycin $20 \mu \mathrm{g} . / \mathrm{ml}$. The base line represents zero, the three dotted lines 100,200 and 300 thousand trophozoites $/ \mathrm{ml}$. The vertical lines represent the trophozoite counts in successive cultures. Conditions: (a) with $\mathrm{I} \cdot 5 \mathrm{ml}$. saline agar slope; $(b)$ with $\mathrm{I} \cdot 5 \mathrm{ml}$. glass rod; $(c)$ with bung in tube; $(d)$ with tube in hydrogen atmosphere of anaerobic jar; $(e)$ with tube open to air.

column was increased in $(d)$ and $(e)$ to that of $(a)$ and $(b)$ by increasing the volume, growth still failed after a few subcultures in hydrogen $(d)$, but succeeded in the tube open to air $(e)$. Therefore, when open to air, the cultures showed a critical surface: height ratio, although they were not inhibited by air in the bunged tube $(c)$. This finding was confirmed many times with various media in various vessels, and with various species of amoebae.

Experiment 2. Drops of amoebic cultures mixed on a tile with $\mathrm{pH}$ indicators showed very rapid alkaline increase suggestive of loss of $\mathrm{CO}_{2}$. On releasing the bottle caps, bubbles rose from below the base of the slope, showing that gas had been retained under pressure. Abundance of $\mathrm{CO}_{2}$ was shown in the cultures by passing a stream of hydrogen into lime water. For rough estimations, overlays from cultures in medium BRS were pooled, and $10 \mathrm{ml}$. titrated with $0.05 \mathrm{~N}-\mathrm{Na}_{2} \mathrm{CO}_{3}$ from $\mathrm{pH} 7$ to maximum colour with phenolphthalein (corresponding to excess $\mathrm{Na}_{2} \mathrm{CO}_{3}$ ); this took $23 \mathrm{ml}$; ; blank titration with medium BRS from $\mathrm{pH} 7$ took $6 \mathrm{ml}$. Since I ml. of $0.05 \mathrm{~N}-\mathrm{Na}_{2} \mathrm{CO}_{3}$ absorbs $0.001 \mathrm{I} \mathrm{g}$. $\mathrm{CO}_{2}$, this gives $\mathrm{I} \cdot 87 \mathrm{~g}$. $\mathrm{CO}_{2} / 1$. culture, if all the acidity in this range were due to $\mathrm{CO}_{2}$.

Experiment 3. Other gas-phase experiments were done with liquid BRS + starch cultures in $8 \times 2.5 \mathrm{~cm}$. one-ounce glass bottles closed by screw caps when required (incubation in a water bath at $37^{\circ}$ ). Bubbling gases through these cultures was un- 
successful, and gas was therefore passed through a reservoir to lessen pressure changes, to emerge from a nozzle $2 \mathrm{~cm}$. above the level of medium in an uncapped bottle. Each run of 4 days comprised four bottles containing equal amounts of medium, starch, antibiotic when needed, and inoculum. Two bottles received gases; the third was capped and the fourth uncapped as control. Amoebae were counted daily in a haemocytometer. The gas flow was kept at about I 1./hr. Culture volumes were restored daily by adding water. These experiments were to compare the effects of carbon dioxide and of oxygen as shown in Fig. 2. The following results were obtained with three runs.

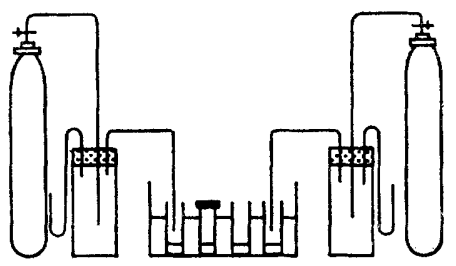

Fig. 2. Diagram of Expt. 3. Passage of gas from cylinder through jar with manometer tube to issue above liquid culture in bottle placed in water bath at $37^{\circ}$. Each run comprised two such arrangements (for comparison of two gases), accompanied by control cultures in capped and uncapped universals.

(I) Four $9 \mathrm{ml}$. volumes of medium BRS $\mathrm{I} / 5$ in medium $\mathrm{R}+$ erythromycin $7 \mu \mathrm{g} . / \mathrm{ml}$. + starch were inoculated with Entamoeba histolytica. Amoebic counts (48 hr) were $27,500 / \mathrm{ml}$. with $5 \%(\mathrm{v} / \mathrm{v}) \mathrm{CO}_{2}$ in oxygen, nil with oxygen, nil in uncapped control and $250,000 / \mathrm{ml}$. in the capped control. (2) With the same amoebic strain and the gases as above, with $9 \mathrm{ml}$. volumes of undiluted medium BRS containing erythromycin $70 \mu \mathrm{g} . / \mathrm{ml}$. + starch, the amoebae $/ \mathrm{ml}$. (maximum at $48 \mathrm{hr}$ ) were: nil for the uncapped control; 20,000 for $\mathrm{O}_{2} ; 360,000$ for the $\mathrm{O}_{2}+\mathrm{CO}_{2} ; 570,000$ for the capped control. (3) With Endolimax nana, $3.5 \mathrm{ml}$. volumes of undiluted medium BRS with erythromycin $33 \mu \mathrm{g} . / \mathrm{ml}$. + starch, and gases $\mathrm{O}_{2}$ and $\mathrm{CO}_{2}$, the amoebae $/ \mathrm{ml}$. (maximum at $72 \mathrm{hr}$ ) were: 20,000 in uncapped control, 20,000 in $\mathrm{O}_{2} ; \mathrm{I} 10,000$ in $\mathrm{CO}_{2} ; 170,000$ in the capped control.

Nelson \& Jones (1964) recorded improvement in amoebic growth by the use of $\mathrm{CO}_{2}+$ bicarbonate buffer. From the present experiments it was at first concluded that $\mathrm{CO}_{2}$ was necessary for amoebic growth; but it became clear as the work proceeded that inhibition of amoebic growth under these experimental conditions was due to the culture becoming alkaline because of the growth of a pellicle of aerobic bacteria. The pellicles on the cultures of Expt. 3 incubated in a mixture of $\mathrm{CO}_{2}$ and $\mathrm{O}_{2}$ were usually just detectable as very thin transparent skins, while the thick white rings of those without $\mathrm{CO}_{2}$ were striking, and when bromthymol blue was added, the downward spread of an alkaline reaction was seen. The phenomenon was like that on which Simmons (1926) based his citrate + salts + bromthymol blue agar test for distinguishing Aerobacter aerogenes by the development of a blue colour, which did not occur when the culture was sealed; that is when $\mathrm{CO}_{2}$ was retained above the surface of the medium; the development of carbonate from organic acids (Ayers \& Rupp, I9I8) in presence of abundant oxygen was inhibited by relatively small amounts of $\mathrm{CO}_{2}$.

Experiment 4. Serial cultivation of amoebae on BR-based medium in the anaerobic jar gave variable numbers of positive subcultures on different occasions, but always 
failed eventually. This was apparently due to progressive diminution of the bacterial flora because of oxygen lack. It also occurred when the jar was filled with $\mathrm{CO}_{2}$ instead of $\mathrm{H}_{2}$, and when the hydrogen-filled jar contained a $\mathrm{CO}_{2}$ absorbent. Thus absence of $\mathrm{O}_{2}$ from the gas phase prevented the growth of aerobic bacteria which promoted amoebic growth, provided that excessive alkali production did not occur. This was corroborated by the parallel effect on amoebic growth observed throughout this work of anaerobiosis or $(a)$ partial $\mathrm{CO}_{2}$ atmosphere, and $(b)$ chemical antibiotics; both factors increased amoebic growth by restraining bacterial growth to a point beyond which they lessened it. Also, because of this effect, optimal concentrations of antibiotic were lower when $\mathrm{CO}_{2}$ was added to the gas phase above the culture.

Experiment 5. Since the above experiments made it likely that the effect of the agar slope in the amoebic cultures was to establish a $\mathrm{pH}$ gradient by retaining $\mathrm{CO}_{2}$, thus preventing alkalinization of the culture sediment from above while permitting aerobic bacterial growth at the surface, it seemed that the slope should be replaceable for longterm maintenance, by the alternate stimulation and repression of the growth of the aerobic bacteria. An experiment was made in which a strain of Entamoeba histolytica was maintained for 3 months without recourse to a saline agar slope by changing from shallow to deep conditions and vice versa. The rubber-capped $\mathrm{I} 20 \times \mathrm{I} 4 \mathrm{~mm}$. tubes from (Capon \& Heaton) transfusion sets were used with $9 \mathrm{ml}$. volumes of liquid medium for the deep conditions, which proved necessary once for every three shallow subcultures of $3 \mathrm{ml}$. volumes in one-ounce bottles.

The necessity for starch grains. Media were developed in which other components, e.g. living Trypanosoma cruzi in the medium of Phillips (I962), replaced living bacteria; in such media, starch particles appear to be unnecessary. But in the medium described above, no amoebic growth was ever obtained without particulate starch. This was tested for all the parasitic amoebae: the substitution of sugars, dextrin or soluble starch was ineffective in promoting the growth of any species in the absence of starch grains. In confirmation, an experiment with Entamoeba histolytica may be quoted. Trophozoites in a faecal specimen were observed to ingest a yeast. These trophozoites were isolated, grown separately and added to cultures of the amoeba in presence and in absence of starch. Without starch, the yeast was not ingested and the amoebae died; with starch, the yeast was ingested in vitro as it had been in vivo.

\section{DISCUSSION}

I have found only one report of previous work aimed to find an 'amoebic growth factor': Nakayama (1958) used a method, like that described here, of adding organic supplements to citrate + Ringer solution overlaying an agar slope. His conclusion is opposed to mine, since he found that protein preparations could be replaced by a variety of soluble protein breakdown products (e.g. proteose, glucosamine). It could be argued from the present results that particulate as opposed to soluble protein is required for amoebic nutrition. Even in 'clear liquid serum' medium a little coagulum was always produced.

Haematoxylin stains commonly show bacteria to be adherent to trophozoites from any source, and the probable ingestion of bacteria by Entamoeba histolytica has been confirmed by electron micrographs of bacteria in food vacuoles (Fletcher, Maegraith \& Jarumilinta, 1962). 'Nests' (Balamuth \& Howard, 1946), and 'crowding' of tropho- 
zoites (Everitt, 1950), were terms used by these workers, without explanation. In the medium described in the present paper amoebic bunches (such as those shown in P1. I, figs. I-3) were seen to be satellites upon bacterial colonies, parts of which often persisted as wisps, binding two or three trophozoites together after separation from the bunch. The siting of the amoebae thus followed that of the accompanying bacteria; the prominence of bunching seen in the present work was possibly due to the favouring of bacterial growth in coherent networks (see Pl. I, fig. 3). Thus a scheme for the processes of growth in the type of amoebic culture described here might be formulated as follows. (I) At some points in the sediment there is focal decrease of $\mathrm{pH}$ value (perhaps due to liberated $\mathrm{CO}_{2}$, held under the butt of the agar slope) sufficient to allow bacterial attack on starch grains. (2) Enough acid is formed from the starch to permit the coating of growing bacteria by protein (analogous to the coating of red blood cells for phagocytosis), from which trophozoites, by ingestion of such bacteria, obtain the ability ('growth factor') to ingest and metabolize grains of starch, which iodine staining shows to be important in their metabolism on the present medium. (3) The amoebae congregate and reproduce on the bacterial colonies, ingesting starch rapidly and possibly stimulating further bacterial growth in their neighbourhood by dextrin formation. (4) The break up of the amoebic clusters follows that of the bacterial colonies on which the amoebae are sited; this seems to be associated with further acid production. This scheme suggests that 'protein-conditioning' of bacteria for ingestion constitutes a difference between parasitic amoebae which require it, and free-living amoebae, which do not.

The author is indebted to the Research Committee of the South East Metropolitan Regional Hospital Board for a grant to cover technical assistance, to the Seamen's Hospital Society and Mr D. A. C. Price for continuing this grant, and to the successive assistance of Mrs Margaret Skeates, Mrs Ann Newman, Mrs Mary Gray and Miss Patricia Ng.

\section{REFERENCES}

Ayers, S. H. \& RUPP, P. (1918). Simultaneous acid and alkaline bacterial fermentations from dextrose and the salts of organic acids respectively. J. infect. Dis. 23, 188.

Balamuth, W. \& Howard, B. (1946). Biological studies on Entamoeba histolytica: I. The growth cycle of populations in a mixed bacterial flora. Am. J. trop. Med. 26, 77I.

Cole, S. W. (1919). Practical Physiological Chemistry, 5th ed. Cambridge: W. Heffer and Sons Ltd.

Dolkart, R. E. \& HalPERn, B. (1958). A new monophasic medium for the cultivation of Entamoeba histolytica. Am. J. trop. Med. Hyg. 7, 595.

EVERITT, M. G. (1950). The relationship of population growth to in vitro encystation of Entamoeba histolytica. J. Parasit. 36, 586.

Fletcher, K. A., Mafgraith, B. G. \& Jarumilinta, R. (1962). Electron microscope studies of trophozoites of Entamoeba histolytica. Ann. trop. Med. Parasit. 56, 496.

HaWk, P. B. (1923). Practical Physiological Chemistry, 8th ed. London: J. and A. Churchill.

NaKayamA, A. (1958). Studies on the culture medium of Entamoeba histolytica. Yokohama med. Bulletin. 9, 290.

Nelson, E. C. \& Jones, M. M. (1964). Cultivation of Entamoeba histolytica on carbon dioxidebicarbonate buffer system media. Am. J. trop. Med. Hyg. 13, 667.

PrinlIPs, B. P. (1962). Further studies with amoeba-trypanosome cultures. Am. J. trop. Med. Hyg. II, 6.

Robinson, G. L. (195I). The haemolysin of Bact. coli. J. gen. Microbiol. 5, 788.

Simmons, J. S. (I926). A culture medium for differentiating organisms of typhoid colon aerogenes group. J. infect. Dis. 39, 209.

SINGH, B. N., DAS, S. R. \& SAXENA, U. (1963). A simple and reliable method for obtaining viable sterile cysts of Entamoeba histolytica from human faeces for monobacterial culture. Ann. Biochem. exp. Med. 23, 51 . 
. 


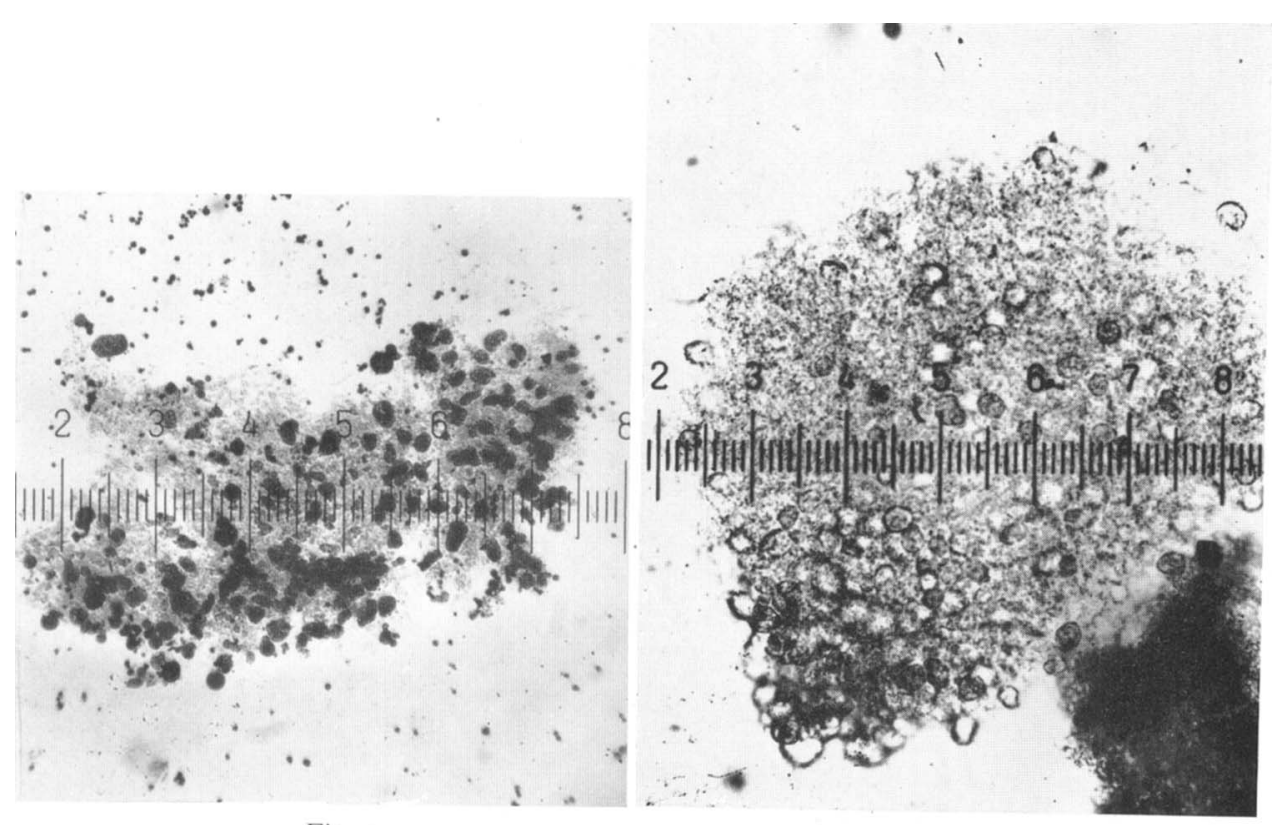

Fig. I

Fig. 2

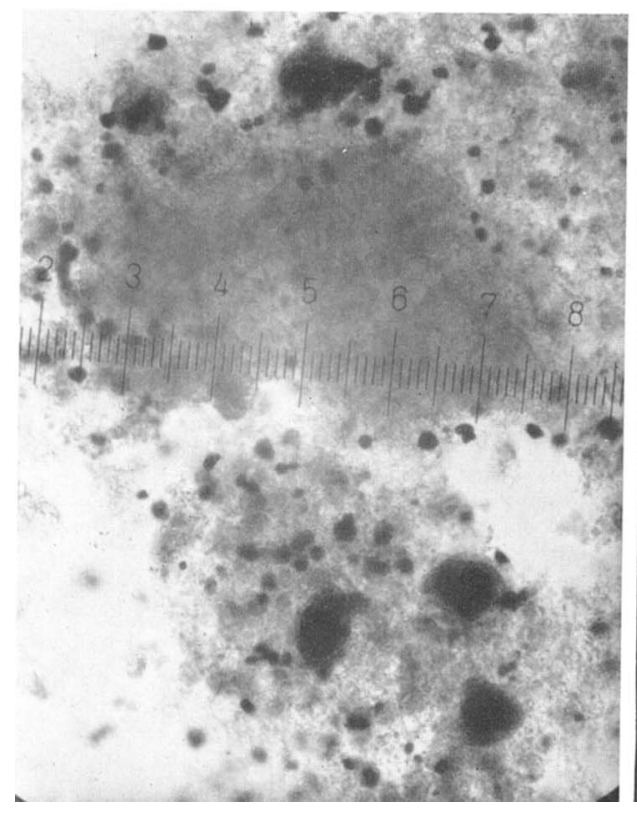

Fig. 3

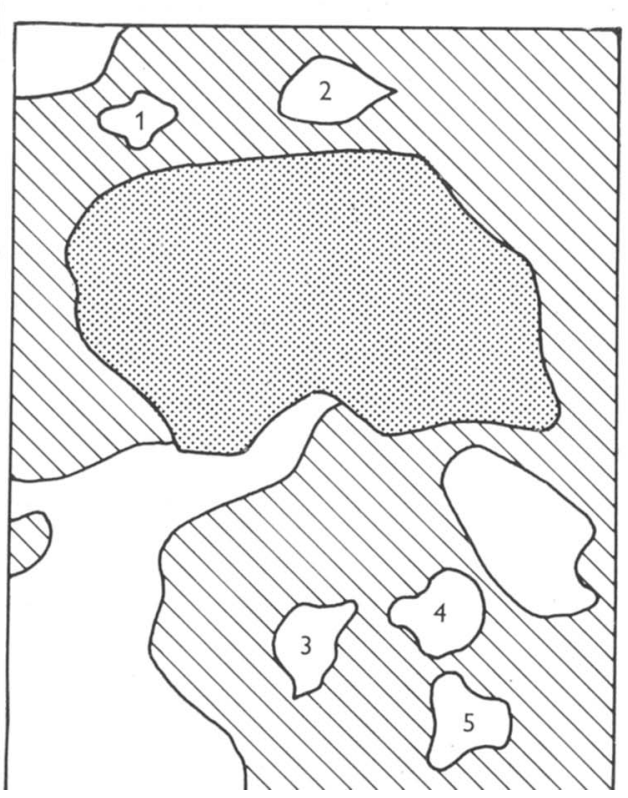

Fig. 4 
SMEDLEY, S. R. (1956). A method of freeing cultures of Entamoeba histolytica from contamination with Blastocystis. Trans. R. Soc. trop. Med. Hyg. 50, 232.

Winzler, R. J., Devor, A. W., MehL, J. W. \& SmYth, I. M. (1948). Studies on the mucoproteins of human plasma. I. Determination and isolation. J. clin. Invest. 27, 609.

\section{EXPLANATION OF PLATE}

Fig. I. Entamoeba histolytica (12353/60) culture. Trophozoites clustered on bacterial colony. Wet preparation in iodine. One scale division $=12 \cdot 2 \mu$.

Fig. 2. Endolimax nana (2687/62) culture. Trophozoites clustered on bacterial colony. Wet preparation in iodine. One scale division $=3.4 \mu$.

Fig. 3. Entamoeba coli (10390/61) culture. Five trophozoites in bacterial network formed around (denser) fragment of metaprotein. Wet preparation in iodine. One scale division $=3.4 \mu$.

Fig. 4. Diagram of Fig. 3. Bacterial network striated, protein fragment shaded and Entamoeba coli numbered. 